\title{
Kinetic Study on Double Isomerization Polymerization of 2-(1-Pyrrolidinyl)-2-oxazoline
}

\author{
Masatoshi Miyamoto, ${ }^{*}$ Masao Morimoto, ${ }^{\dagger}$ and Takeo SaEgusa ${ }^{\dagger \dagger}$ \\ Department of Chemical and Biochemical Engineering, Faculty of Engineering, \\ Toyama University, Gofuku, Toyama 930, Japan \\ ${ }^{\dagger}$ Department of Synthetic Chemistry, Faculty of Engineering, Kyoto University, \\ Yoshida, Sakyo-ku, Kyoto 606, Japan \\ ${ }^{\dagger+}$ KRI International, Inc., 17 Chudoji-Minami-Machi, \\ Shimogyo-ku, Kyoto 600, Japan
}

(Received March 22, 1993)

\begin{abstract}
In the present study kinetic experiments on the polymerizations of 2-(1pyrrolidinyl)-2-oxazoline (1) initiated with methyl iodide and with methyl $p$-toluenesulfonate were carried out to confirm the polymerization mechanisms: methyl iodide initiates "double isomerization polymerization" (DIP) of 1 while methyl tosylate leads to the usual ring-opening isomerization polymerization of $\mathbf{1}$. The former polymerization characteristically contains the isomerization of propagating species during propagation. The initial intermediate species in each polymerizations was isolated and used as model compounds of propagating species to determine the rate of polymerization. The kinetic experiments for DIP revealed that the initiation occurred more rapidly than each of the isomerization reactions of the initial propagating species and the propagation. The relative contribution of propagating isomers on the polymerization were also evaluated.
\end{abstract}

KEY WORDS Double Isomerization Polymerization / Single Isomerization Polymerization / 2-(1-Pyrrolidinyl)-2-oxazoline / Kinetics / 3-Methyl-2-(1pyrrolidinyl)-2-oxazolinium Salts / Spiro-Ammonium Salts /

In previous papers we described a novel mode of ring-opening isomerization polymerization of cyclic pseudoureas such as 2-(1pyrrolidinyl)-2-oxazoline (1). ${ }^{1,2}$ The polymerizations of 1 give two quite different polymers from each other via cationic mechanisms: poly $\{[N-(1-$ pyrrolidinylcarbonyl)imino $]$ ethylene\} (2) was produced by the ring-opening isomerization polymerization ("SIP" meaning single isomerization polymerization) of 1 with methyl trifluoromethanesulfonate (MeOTf) or methyl $p$-toluenesulfonate (tosylate) (MeOTs). In this SIP the 2-oxazoline ring in $\mathbf{1}$ is opened as in the well-known case of 2-alkyl- or 2-aryl-2-oxazolines. ${ }^{3}$ Poly[(1,3-diazolidin-2on-1,3-diyl)tetramethylene] (3) was produced by the new mode of cationic ring-opening isomerization polymerization ("double isomerization polymerization" (DIP)) initiated by an alkyl halide, methyl iodide or benzyl chloride or bromide. The propagation in the

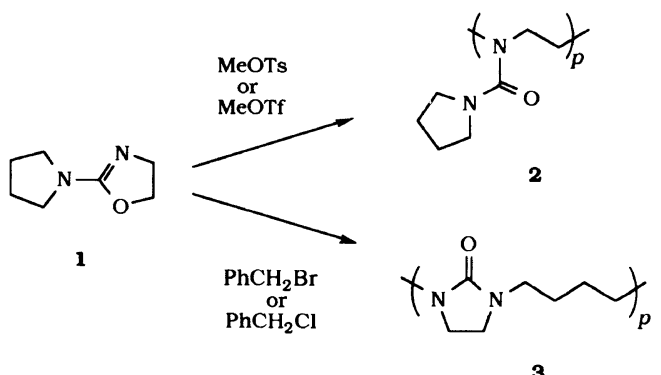

Scheme 1.

\footnotetext{
* To whom correspondence should be addressed.
} 
DIP accompanies isomerization reactions of propagating species.

The polymerization mechanism of DIP is illustrated in Scheme 2. The initially formed propagating species in both modes of polymerization are oxazolinium salts, 4 .

In DIP, the isomerization of 4 to an spiro-ammonium species $\mathbf{6}$ and, then, a covalent species 7 occurs since the counteranion of 4, a halide anion, is nucleophilic enough to catalyze the isomerization reactions. The counter anion attacks the 5-position of $\mathbf{4}$ to give a covalent type alkyl halide species 5, which further isomerizes to 6.6 is electrophilic enough to accept the attack of the counter anion and it further isomerizes to another covalent species 7 . The propagation from 6 or 7 results in the formation of the 3 unit (main-chain-type unit). With alkyl sulfonate initiator, the oxazolinium species, 4 , is stable due to the poor nucleophilicity of counteranion and directly concerns the propagation, which generates the $\mathbf{2}$ unit (pendanttype unit).

The above polymerization mechanism was confirmed from the isolation of initial products, 3-methyl-2-(1-pyrrolidinyl)-2-oxazolinium iodide (4a) and tosylate (4b) and subsequent investigation on their isomerization reactions. ${ }^{1}$ However, the relative contribution of the two possible propagating species, 6 and 7, to the propagation of DIP has not been clear.

The present paper describes kinetic studies on the DIP and SIP of 1 to establish the above polymerization mechanism. We reported that a series of 2-amino-2-oxazolines as well as 2-amino-5,6-dihydro-4H-1,3-oxazines undergoes the DIP and alkyl halides, i.e., methyl iodide and benzyl bromide and chloride are effective for the DIP. ${ }^{1,2,4}$ But, we selected only one combination of the DIP system for the kinetic analysis since the polymerization pathway of DIP is so complicated and many rate constants must be determined to grasp the total image of the polymerization. The polymerization of $\mathbf{1}$ with methyl iodide is not a representative case of the DIP: it gives a polymer of mixed structure, which means the propagation reactions for the DIP and SIP occurs simultaneously in this system (Scheme 3).

We consider this system the most proper to

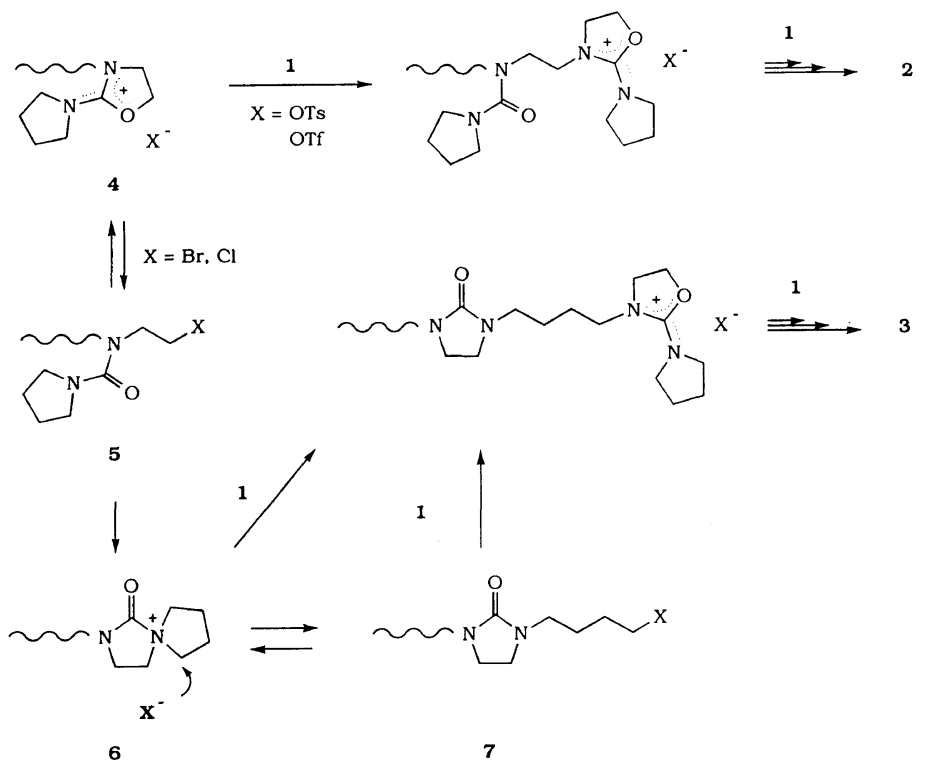

Scheme 2. 


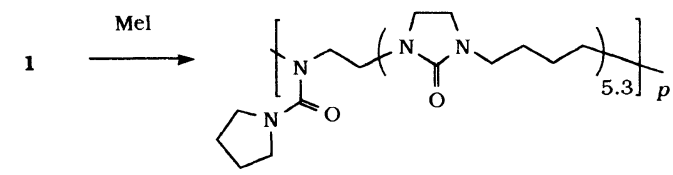

Scheme 3.

discuss the characteristics of the DIP because the relative rates of propagation in the DIP and SIP can be estimated from the polymer composition.

Although termination and chain transfer reactions are susceptible in the DIP of $\mathbf{1}$, the present paper does not deal with these problems to simplify the polymerization mechanism.

\section{EXPERIMENTAL}

\section{Materials}

2-(1-Pyrrolidinyl)-2-oxazoline (1), 3-methyl2-(1-pyrrolidinyl)-2-oxazolinium iodide (4a) and tosylate (4b), and 3-methyl-1-azonia-3azaspiro[4.4]nonan-2-one iodide (6a) were prepared as described in the previous paper. ${ }^{1}$ Silver tosylate was used as received. Nitrobenzene- $d_{5}$ was dried over molecular sieves $3 \AA$ and used without distillation. Other solvents as well as methyl iodide, methyl tosylate, and $n$-butyl iodide were commercially available ones, which were dried by the conventional methods and distilled under nitrogen. The solvents were stored over molecular sieves $3 \AA$ after distillation.

\section{Measurements}

${ }^{1} \mathrm{H}$ NMR spectra were recorded on a 60 $\mathrm{MHz}$ Hitachi R-600 or $200 \mathrm{MHz}$ Varian Gemini-200 NMR spectrometer. ${ }^{13} \mathrm{C}$ NMR spectra were recorded on a Hitachi R-900 NMR spectrometer operated at $22.5 \mathrm{MHz}$. FT-IR spectra were obtained on a Perkin Elmer 1600 infrared spectrometer. GPC analysis was performed by a Tosoh HLC 8020 system using a Shodex AC803 column in chloroform. Number average molecular weights of the samples were measured by a vapor pressure osmometer (Corona Model 117) in chloroform at $35^{\circ} \mathrm{C}$.

\section{Preparation of 3-Methyl-1-azonia-3-azaspiro-} [4.4]nonan-2-one Iodide (6b)

All operations were carried out under nitrogen. In a test tube equipped with a threeway stop-cock were placed $0.762 \mathrm{~g}$ of $6 \mathrm{a}$ and $4.5 \mathrm{ml}$ of acetonitrile. To the mixture were added $15 \mathrm{ml}$ of $0.4 \mathrm{~N}$ silver tosylate in acetonitrile under cooling with ice. The mixture was stirred overnight in darkness. The produced yellow precipitate (silver iodide) was filtered and the filtrate was evaporated to dryness. The residue was dissolved into nitromethane and the residual white precipitate (silver tosylate) was filtered. The filtrate was poured into diethyl ether to precipitate the product. The supernatant layer was decanted off and the residual crude product was further purified by reprecipitation from nitrobenzene (solvent) to diethyl ether (non-solvent). After drying in vacuo, $0.645 \mathrm{~g}$ of $\mathbf{6 b}$ was obtained as white crystals ( $73 \%$ yield). ${ }^{1} \mathrm{H} \mathrm{NMR}\left(\mathrm{CD}_{3} \mathrm{CN}\right)$ : 2.05-2.30 (m, 4H, $\left.\mathrm{NCH}_{2} \mathrm{CH}_{2} \mathrm{CH}_{2} \mathrm{CH}_{2}\right), 2.37$ (s, $\left.3 \mathrm{H}, \mathrm{ArCH}_{3}\right), 2.98\left(\mathrm{~s}, 3 \mathrm{H}, \mathrm{NCH}_{3}\right), 3.55$ $3.82\left(\mathrm{~m}, 6 \mathrm{H}, \quad \mathrm{NCH}_{2} \mathrm{CH}_{2} \mathrm{CH}_{2} \mathrm{CH}_{2}\right.$ and $\left.\mathrm{NCH}_{2} \mathrm{CH}_{2} \mathrm{O}\right), 3.87$ (t, 2H, $\left.\mathrm{NCH}_{2} \mathrm{CH}_{2} \mathrm{O}\right)$, $7.10-7.72\left(\mathrm{~m}, 4 \mathrm{H}\right.$, aromatic protons). ${ }^{13} \mathrm{C}$ NMR $\left(\mathrm{CDCl}_{3}\right): 21.4\left(\mathrm{ArCH}_{3}\right), 23.4,32.8$ $\left(\mathrm{NCH}_{3}\right), 44.4,56.9,62.2,125.1,127.9,138.1$, 143.1, 153.2. IR $\left(\mathrm{CHCl}_{3}\right) 2938,1814\left(v_{\mathrm{C}=\mathrm{N}}\right)$, $1424,1203 \mathrm{~cm}^{-1}$.

\section{Kinetics}

The procedure for the determination of the rate of initiation in the DIP $\left(k_{i a}\right)$ at $25^{\circ} \mathrm{C}$ is as follows. In an NMR tube equipped with a three-way stopcock were placed $9.6 \mathrm{mg}$ $(68.5 \mu \mathrm{mol})$ of $1,0.60 \mathrm{ml}$ of nitrobenzene- $d_{5}$, $2.5 \mathrm{mg}$ of benzene (as an internal standard), and $26.5 \mathrm{mg}(187 \mu \mathrm{mol})$ of methyl iodide under cooling at $-78^{\circ} \mathrm{C}$. The tube was sealed and kept at $25{ }^{\circ} \mathrm{C}$. The progress of reaction was monitored directly by ${ }^{1} \mathrm{H}$ NMR spectroscopy and the instantaneous concentrations of the 
Table I. Conditions for the determination of rate constants ${ }^{\mathrm{a}}$

\begin{tabular}{|c|c|c|c|c|c|c|}
\hline \multirow{4}{*}{$\begin{array}{c}\text { Rate } \\
\text { constant }\end{array}$} & \multirow{4}{*}{$\frac{\text { Temp }}{{ }^{\circ} \mathrm{C}}$} & \multicolumn{3}{|c|}{ Starting compounds ${ }^{b}$} & \multirow{3}{*}{\multicolumn{2}{|c|}{$\begin{array}{l}\text { Final products }^{\mathrm{b}} \\
{ }^{1} \mathrm{H} \text { NMR signal }{ }^{\mathrm{c}}\end{array}$}} \\
\hline & & & \multirow{3}{*}{$\begin{array}{c}\begin{array}{c}\text { Initial } \\
\text { concentration }\end{array} \\
M\end{array}$} & \multirow[t]{2}{*}{${ }^{1} \mathrm{H}$ NMR signal ${ }^{\mathrm{c}}$} & & \\
\hline & & & & & & \\
\hline & & & & ppm (assignment) & & ppm (assignment) \\
\hline \multirow[t]{2}{*}{$k_{i b}$} & \multirow[t]{2}{*}{35} & 1 & 0.110 & $4.30\left(\mathrm{OCH}_{2}\right)$ & \multirow[t]{2}{*}{$4 b$} & \multirow[t]{2}{*}{$4.55\left(\mathrm{OCH}_{2}\right)$} \\
\hline & & MeOTs & 0.321 & 7.38 and $7.80\left(\mathrm{C}_{6} \mathrm{H}_{4}\right)$ & & \\
\hline \multirow[t]{2}{*}{$k_{p 2}$} & \multirow[t]{2}{*}{80} & 1 & 3.556 & $4.30\left(\mathrm{OCH}_{2}\right)$ & \multirow[t]{2}{*}{$2 \mathbf{a}$} & \multirow[t]{2}{*}{$4.83\left(\mathrm{OCH}_{2}\right.$ of end group $)$} \\
\hline & & MeOTs & 0.708 & 7.38 and $7.80\left(\mathrm{C}_{6} \mathrm{H}_{4}\right)$ & & \\
\hline \multirow[t]{2}{*}{$k_{i a}$} & \multirow[t]{2}{*}{25} & 1 & 0.113 & $3.80\left(\mathrm{NCH}_{2} \mathrm{CH}_{2} \mathrm{O}\right)$ & \multirow[t]{2}{*}{$\mathbf{4 a}$} & \multirow[t]{2}{*}{$3.47\left(\mathrm{NCH}_{3}\right)$} \\
\hline & & MeI & 0.309 & 2.18 & & \\
\hline \multirow[t]{2}{*}{$k_{46}$} & \multirow[t]{2}{*}{55} & \multirow[t]{2}{*}{$\mathbf{4 a}$} & \multirow[t]{2}{*}{0.240} & \multirow[t]{2}{*}{$3.84\left(\mathrm{CH}_{2} \mathrm{CH}_{2} \mathrm{CH}_{2} \mathrm{CH}_{2}\right)$} & $\mathbf{6 a}$ & $3.09\left(\mathrm{CH}_{3}\right)$ \\
\hline & & & & & $7 \mathbf{a}$ & $2.71\left(\mathrm{CH}_{3}\right)$ \\
\hline \multirow{3}{*}{$\begin{array}{c}k_{67} \text { and } k_{76} \\
k_{p 6}\end{array}$} & 55 & $6 \mathbf{a}$ & 0.110 & $3.09\left(\mathrm{CH}_{3}\right)$ & $7 \mathbf{a}$ & $2.71\left(\mathrm{CH}_{3}\right)$ \\
\hline & \multirow[t]{2}{*}{80} & 1 & 0.314 & $4.30\left(\mathrm{OCH}_{2}\right)$ & \multirow[t]{2}{*}{8} & \multirow[t]{2}{*}{$2.72\left(\mathrm{NCH}_{3}\right)$} \\
\hline & & 6b & 0.343 & $3.09\left(\mathrm{NCH}_{3}\right)$ & & \\
\hline \multirow[t]{2}{*}{$k_{p 7}$} & \multirow[t]{2}{*}{80} & 1 & 0.214 & $3.80\left(\mathrm{NCH}_{2} \mathrm{CH}_{2} \mathrm{O}\right)$ & $4 \mathbf{c}$ & $4.83\left(\mathrm{OCH}_{2}\right)$ \\
\hline & & $\mathrm{BuI}$ & 0.185 & $3.20\left(\mathrm{ICH}_{2}\right)$ & $\mathbf{4 c}$ & $4.83\left(\mathrm{OCH}_{2}\right)$ \\
\hline
\end{tabular}

${ }^{\text {a }}$ In nitrobenzene- $d_{5}$.

b Abbriviations are shown in the text.

c Signals used for determination of substrates.

monomer (from the $\mathrm{NCH}_{2} \mathrm{CH}_{2} \mathrm{O}$ triplet at $\delta$ $3.73)$, methyl iodide $(\delta 2.00)$ and the $1: 1$ adduct 4a (from the $\mathrm{NCH}_{3}$ singlet at $\delta$ 3.47) were obtained from the relative intensities of their characteristic peaks cited in parentheses against the peak of benzene. The reaction system was homogeneous throughout the kinetic run.

Kinetic measurements to determine other individual rate constants were also carried out in NMR tubes. The peaks used for the determination of substrates were summarized in Table I.

The procedure for the determination of the rate of polymerization in the DIP is as follows. In a test tube equipped with a threeway stopcock and a magnetic stirrer bar were placed $0.453 \mathrm{~g}(3.23 \mathrm{mmol})$ of $1, \quad 3.0 \mathrm{ml}$ of nitrobenzene, $0.166 \mathrm{~g}$ of mesitylene (as an internal standard for GPC analysis), and $51.7 \mathrm{mg}(0.365 \mathrm{mmol})$ of methyl iodide under cooling at $-78^{\circ} \mathrm{C}$. The mixture was kept at $80^{\circ} \mathrm{C}$. At appropriate intervals, $30 \mathrm{ml}$ of the mixture were withdrawn from the reaction system and poured into $1 \mathrm{ml}$ of diethyl ether containing $0.016 \mathrm{~g}$ of pyridine. The supernatant ether layer was subjected to the GLC analysis (Silicon DC 550, 2m) to determine the conversion of the monomer.

\section{RESULTS AND DISCUSSION}

As shown in Scheme 2, the polymerization mechanism of DIP is very complicated. Therefore, it was quite difficult to determine each rate constants from the real polymerization system and a proper model compound for each intermediate species was required. We have shown that the initial intermediate species in the DIP and SIP processes can be isolated. ${ }^{1}$ These compounds are considered proper models for the corresponding propagating species. The kinetic studies using these model compounds were carried out in nitrobenzene- $d_{5}$ at $80^{\circ} \mathrm{C}$ or done at lower temperatures and the rate constants at $80^{\circ} \mathrm{C}$ were estimated by extrapolation since polymerization experiments have been carried out in nitrobenzene at $80^{\circ} \mathrm{C}$ or above. ${ }^{1} \mathrm{H}$ NMR 
spectroscopy was applied for the determination of the concentrations of starting and producing materials. This technique has already been applied successfully to the determination of rate constants for the polymerizations of 2-oxazolines and 5,6-dihydro-4H-1,4oxazines. ${ }^{5-7}$

\section{Initiation}

The intermediate species first formed in the DIP of 1 with MeI is an ionic 1:1 adduct, 3-methyl-2-(1-pyrrolidinyl)-2-oxazolinium iodide $4 \mathbf{a}$. To determine the rate of formation of the salt, i.e., the rate of initiation $\left(k_{i a}\right)$ in this system, 1 was reacted with 2.7 fold excess methyl iodide in nitrobenzene- $d_{5}$ at $25^{\circ} \mathrm{C}$ and the consumptions of 1 and $\mathrm{MeI}$ and generation of $4 a$ were directly measured by ${ }^{1} \mathrm{H}$ NMR spectroscopy (see Experimental section). It is unusual to use excess initiator for the determination of $k_{i}$, but it was required to suppress the subsequent isomerization and propagation reactions, which complicate the in situ ${ }^{1} \mathrm{H}$ NMR spectrum of the system.

$$
1+\mathrm{MeI} \stackrel{k_{\mathrm{ia}}}{\longrightarrow} \mathrm{N}_{4 \mathrm{a}}^{\mathrm{Na}_{3}} \mathrm{I}^{-}
$$

Figure 1 shows the time-course of the concentrations of $\mathbf{1}, \mathrm{MeI}$, and $\mathbf{4 a}$ thus determined. In the figure the consumed amounts of 1 from the initial concentration are also indicated as open triangles, which coincide well with the concentrations of $\mathbf{4 a}$ at the beginning, but overcome them as the reaction proceed. This can be explained by the further isomerization of $4 \mathbf{a}$ to $\mathbf{6 a}$ and, then, 7a (vide infra).

Many kinetic studies on the cationic ring-opening polymerization of 2-alkyl- and 2-aryl-2-oxazolines have been done, which reveal initiation and propagation reactions to be $S_{\mathrm{N}} 2$ type ones. $^{3-6}$ In these systems the rate equations concerning the initiation are expressed as follows.

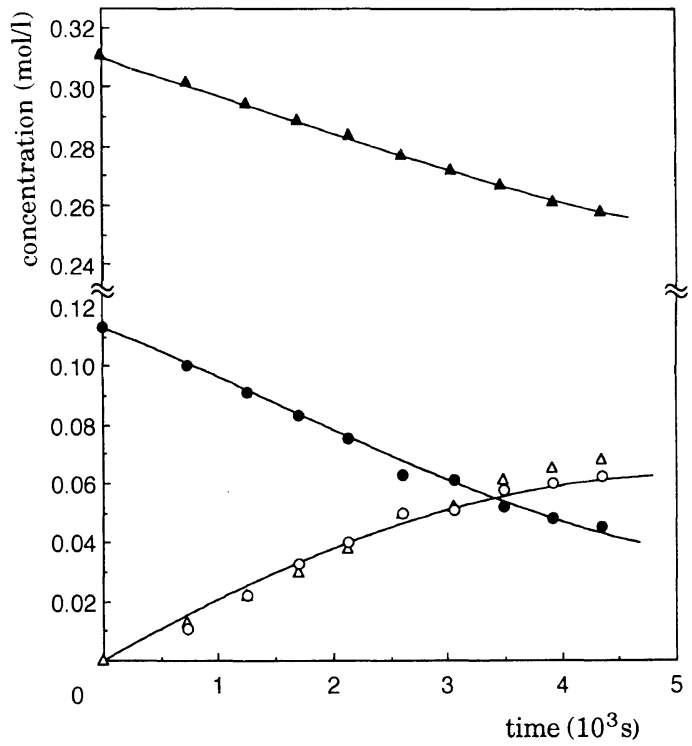

Figure 1. Time-course of the concentrations of $1(\mathbf{O})$, MeI ( $\Delta)$, and 4a $(O)$ in the initiating step of the DIP (in nitrobenzene- $d_{5}$ at $25^{\circ} \mathrm{C}$ ). Open triangles indicate values of $[1]_{0}-[1]$.

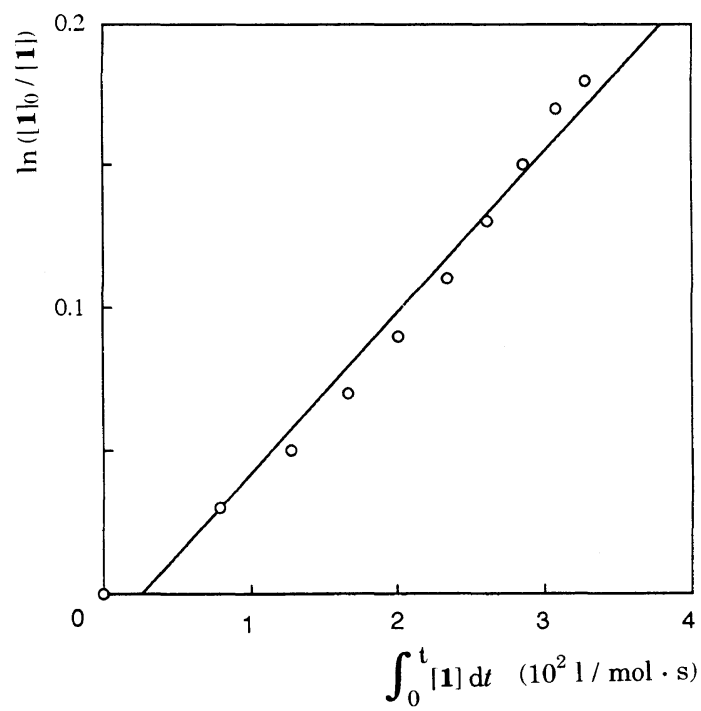

Figure 2. Plot of eq 3 to determine $k_{i a}$ in the initiation of 1 with methyl iodide at $25^{\circ} \mathrm{C}$.

$$
\begin{gathered}
-\frac{\mathrm{d}[\mathrm{I}]}{\mathrm{d} t}=k_{i}[\mathrm{I}][\mathrm{M}] \\
\ln \frac{[\mathrm{I}]_{0}}{[\mathrm{I}]}=k_{i} \int_{0}^{t}[\mathrm{M}] \mathrm{d} t
\end{gathered}
$$


Table II. Rate constants in the DIP of $\mathbf{1}$ with $\mathrm{MeI}^{\mathrm{a}}$

\begin{tabular}{|c|c|c|c|c|c|c|}
\hline \multirow{3}{*}{$\frac{\text { Temp }}{{ }^{\circ} \mathrm{C}}$} & \multicolumn{6}{|c|}{ Rate constants } \\
\hline & $k_{i a}$ & $k_{i b}$ & \multirow{2}{*}{$\frac{k_{46}}{10^{-4} / \mathrm{s}}$} & \multirow{2}{*}{$\frac{k_{p 4}}{10^{-4} 1 \mathrm{~mol}^{-1} \mathrm{~s}^{-1}}$} & \multirow{2}{*}{$\frac{k_{p 6}}{10^{-4} 1 \mathrm{~mol}^{-1} \mathrm{~s}^{-1}}$} & \multirow{2}{*}{$\frac{k_{p 7}}{10^{-4} 1 \mathrm{~mol}^{-1} \mathrm{~s}^{-1}}$} \\
\hline & $10^{-4} 1 \mathrm{~mol}^{-1} \mathrm{~s}^{-1}$ & $10^{-4} 1 \mathrm{~mol}^{-1} \mathrm{~s}^{-1}$ & & & & \\
\hline 15 & 2.7 & & & & & \\
\hline 25 & 6.1 & & & & & \\
\hline 35 & 13 & 14 & 0.10 & 0.083 & 0.018 & 0.29 \\
\hline 45 & & & 0.40 & & & \\
\hline 55 & & & 1.4 & & & \\
\hline 80 & $280^{\mathrm{b}}$ & & $22^{\mathrm{b}}$ & 1.8 & 1.2 & 4.4 \\
\hline
\end{tabular}

a In $\mathrm{C}_{6} \mathrm{D}_{5} \mathrm{NO}_{2}$.

b Extrapolated values according to the Arrhenius equation.

These equations were considered applicable to the initiation for the polymerization of 1 and a linear relationship was observed between the value of the left-hand side of eq 3 and the integral of $[\mathrm{M}]$, which was given by graphical integration on the curve for [1] in Figure 1 (Figure 2). The rate constant of initiation $k_{i a}$ at $25^{\circ} \mathrm{C}$ was obtained from the slope as $6.1 \times 10^{-4} 1 \mathrm{~mol}^{-1} \mathrm{~s}^{-1}$.

The rate constants at 15 and $35^{\circ} \mathrm{C}$ were similarly obtained according to eq 3 and are summarized in Table II. The rate constant at $80^{\circ} \mathrm{C}$ was extrapolated from the three values according to the Arrhenius equation, shown in Table II.

\section{Isomerization of 4 to 6}

The oxazolinium iodide $\mathbf{4 a}$ is thermally unstable and isomerizes to $\mathbf{6 a}$ and, then, 7a upon heating. Our previous work showed that an equilibrium exists between $\mathbf{6 a}$ and $7 \mathbf{a}$, but no backward reaction from $6 \mathrm{a}$ to $4 \mathrm{a}$ proceeds. ${ }^{1}$

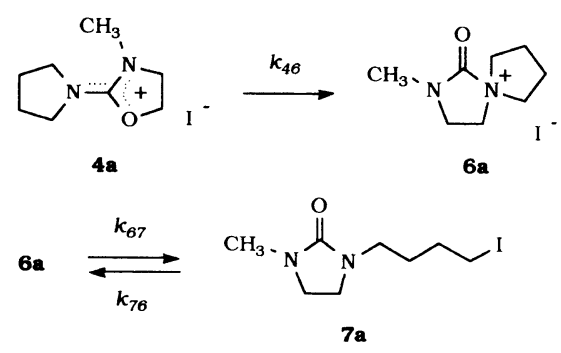

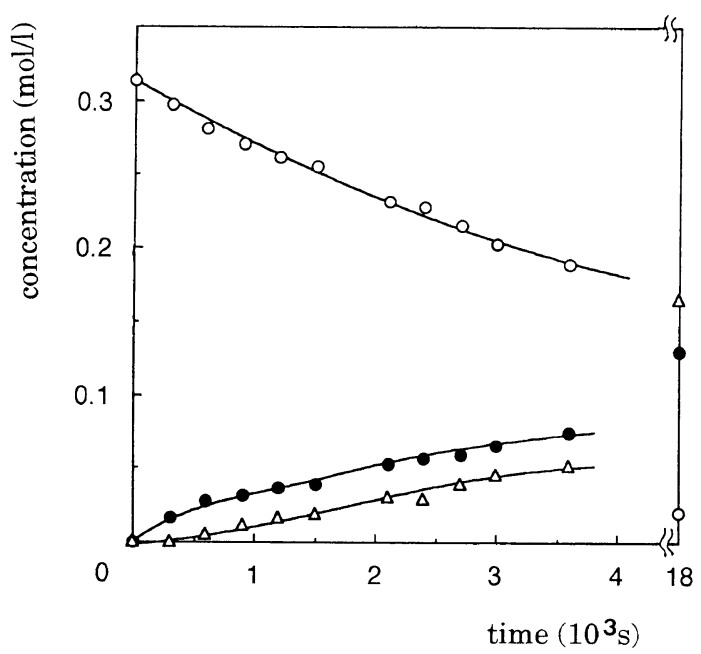

Figure 3. Decrease rate of the concentration of $\mathbf{4 a}(\mathrm{O})$ by isomerization to $6 \mathbf{a}(\triangle)$ and $7 \mathbf{a}(\triangle)$. Data were taken in nitrobenzene- $d_{5}$ at $55^{\circ} \mathrm{C}$.

Figure 3 shows the time-course of the concentrations of $\mathbf{4 a}, \mathbf{6 a}$, and $7 \mathbf{a}$ in nitrobenzene- $d_{5}$ at $55^{\circ} \mathrm{C}$. When $7 \mathbf{a}$ was formed exclusively from $\mathbf{6 a}$, the rate of isomerization of $4 \mathbf{a}$ to $\mathbf{6 a}\left(k_{46}\right)$ was obtained from the plot of eq 7, which is shown in Figure 4.

$$
\begin{gathered}
-\frac{\mathrm{d}[\mathbf{4 a}]}{\mathrm{d} t}=\frac{\mathrm{d}[6 \mathbf{a}]}{\mathrm{d} t}=k_{46}[4 \mathrm{a}] \\
\ln \frac{[4 \mathrm{a}]_{0}}{[4 \mathrm{a}]}=k_{46} t
\end{gathered}
$$




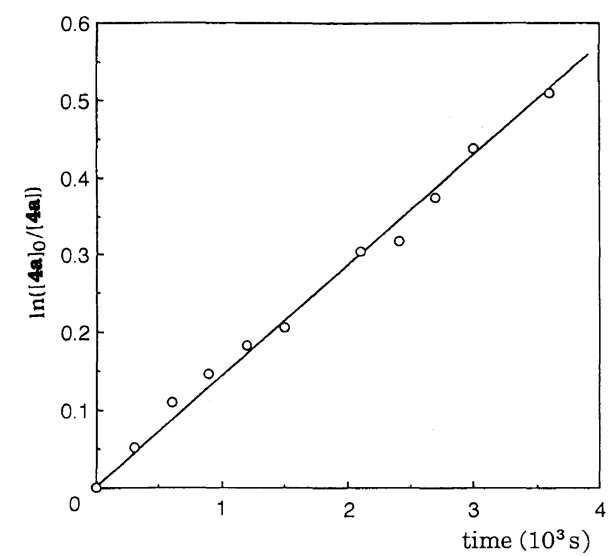

Figure 4. Plot of eq 7 to determine $k_{46}$ in the isomerization of $4 \mathrm{a}$ to $6 \mathrm{a}$ at $80^{\circ} \mathrm{C}$.

The linear relationship observed in the figure clearly shows that the conversion of $\mathbf{4 a}$ to $\mathbf{6 a}$ is the intramolecular isomerization as expected. $k_{46}$ values at 35 and $45^{\circ} \mathrm{C}$ were also determined in a similar manner. These values as well as the value extrapolated to $80^{\circ} \mathrm{C}$ are listed in Table II.

\section{Isomerization between 6 and 7}

Although the isomerization of $4 \mathbf{a}$ to $\mathbf{6 a}$ and $7 \mathbf{a}$ gave an equilibrated mixture of $6 \mathbf{a}$ and $7 \mathbf{a}$, 6a could be isolated as orange needles by cooling the reaction mixture to $-40^{\circ} \mathrm{C}$. The rate of isomerization of $\mathbf{6 a}$ to $7 \mathbf{a}\left(k_{67}\right)$ was determined by heating the isolated $\mathbf{6 a}$ in nitrobenzene- $d_{5}$ at $55^{\circ} \mathrm{C}$. The time-course of the concentrations of both species are shown in Figure 5. An equilibrium between 6a and 7a was attained after $4 \mathrm{~h}$ and the equilibrium constant $(K=\mathbf{7 a} / \mathbf{6 a})$ was determined as 1.2 .

The concentration of $\mathbf{6 a}$ is expressed by the following equations:

$$
\begin{aligned}
-\frac{\mathrm{d}[\mathbf{6 a}]}{\mathrm{d} t} & =k_{67}[\mathbf{6 a}]-k_{76}[7 \mathbf{a}] \\
& =k_{67}[\mathbf{6 a}]-k_{76}\left([6 \mathbf{6}]_{0}-[\mathbf{6 a}]\right) \\
& =\left(k_{67}+k_{76}\right)[6 \mathbf{a}]-k_{76}[6 \mathbf{a}]_{0}
\end{aligned}
$$

The introduction of the equilibrium constant

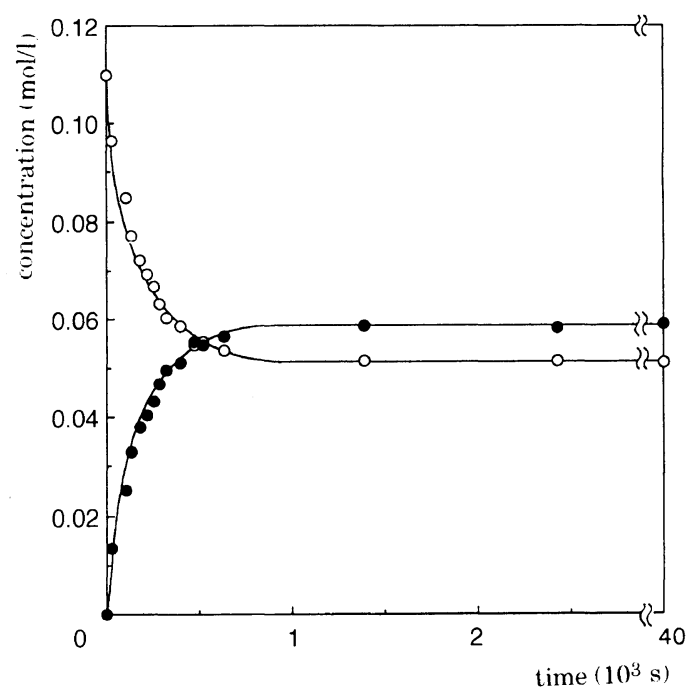

Figure 5. Change of the concentration of $6 \mathbf{a}(\mathrm{O})$ by the isomerization to $7 \mathbf{a}(\mathbf{)})$. Data were taken in nitrobenzene$d_{5}$ at $55^{\circ} \mathrm{C}$.

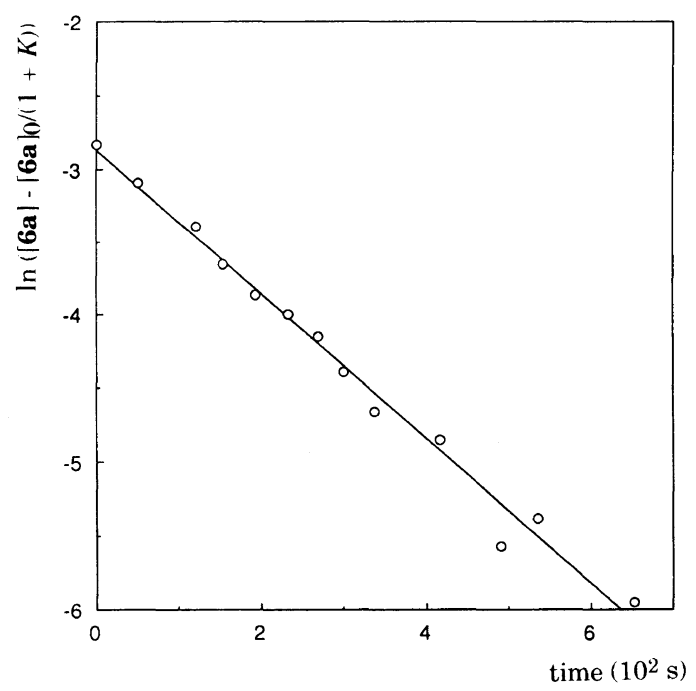

Figure 6. Plot of eq 9 to determine $k_{67}$ and $k_{76}$ in the isomerization between $\mathbf{6 b}$ and $7 \mathbf{a}$ in nitrobenzene- $d_{5}$ at $55^{\circ} \mathrm{C}$.

into eq 8 and subsequent transformation give eq 9.

$$
\begin{aligned}
\ln \left([\mathbf{6 a}]-\frac{[\mathbf{6} \mathbf{a}]_{0}}{1+K}\right)= & -\left(k_{67}+k_{76}\right) t \\
& +\ln \left(\frac{K}{1+K}[\mathbf{6 a}]_{0}\right)
\end{aligned}
$$


Table III. Rate constants for the isomerization of $6 a$ to $7 a^{a}$

\begin{tabular}{|c|c|c|c|c|c|}
\hline \multirow{3}{*}{$\frac{\text { Temp }}{{ }^{\circ} \mathrm{C}}$} & \multirow{3}{*}{$\begin{array}{c}\begin{array}{c}\text { Initial concentration } \\
\text { of } 6 \mathbf{a}\end{array} \\
M\end{array}$} & \multicolumn{2}{|c|}{ Rate constants } & \multirow{2}{*}{\multicolumn{2}{|c|}{$\begin{array}{l}\text { Equilibrium constant } \\
\qquad K=k_{67} / k_{76}\end{array}$}} \\
\hline & & \multirow{2}{*}{$\begin{array}{c}k_{67} \\
10^{-4} / \mathrm{s}\end{array}$} & \multirow{2}{*}{$\begin{array}{c}k_{76} \\
10^{-4} / \mathrm{s}\end{array}$} & & \\
\hline & & & & Found & Calcd $^{c}$ \\
\hline 45 & 0.110 & 0.80 & 1.1 & 0.75 & \\
\hline 55 & 0.110 & 3.0 & 2.6 & 1.2 & \\
\hline 65 & 0.124 & 12 & 7.9 & 1.5 & \\
\hline 80 & 0.124 & $71^{b}$ & $34^{\mathrm{b}}$ & 2.2 & 2.1 \\
\hline 100 & 0.124 & $590^{b}$ & $174^{b}$ & 3.1 & 3.4 \\
\hline
\end{tabular}

a In $\mathrm{C}_{6} \mathrm{D}_{5} \mathrm{NO}_{2}$.

b Extrapolated values according to the Arrhenius equation.

c Calculated from extraporated $k_{67}$ and $k_{76}$.

Figure 6 shows a plot of eq 9 using the data in Figure 5. The rate constants $k_{67}$ and $k_{76}$ were calculated respectively as $3.0 \times 10^{-4}$ and $2.6 \times 10^{-4}\left(1 \mathrm{~mol}^{-1} \mathrm{~s}^{-1}\right)$ from the slope of the line combined with the equilibrium constant.

Similar experiments were carried out at 45 and $65^{\circ} \mathrm{C}$. The reactions at 80 and $100^{\circ} \mathrm{C}$ were so fast that the rate constants could not be determined. However, the equilibrium constants at these temperatures were easily determined, and are shown in Table III. The equilibrium constants at these temperatures could be calculated from the extrapolated rate constants. The good accordance between the calculated and observed equilibrium constants indicates the high reliability of the extrapolated values.

\section{Propagation from 4}

4a, 6a, and 7a directly concern propagation. Propagation via $4 a$ yields the pendant-type unit and that via 6a or 7a yields the main-chain-type unit. To understand the general image of the DIP, each rate constant for the propagation reactions via these species should be determined. However, none can be obtained directly by using these compounds $4 \mathbf{a}, \mathbf{6 a}$, and $7 \mathbf{a}$ due to the isomerization between them. Therefore, model compounds for these species were required.

Since the isomerization reactions were catalyzed by the counteranion, the iodide in the present case, compounds having nonnucleophilic counteranions were available as model compounds for $\mathbf{4 a}$ and $\mathbf{6 a}$. In kinetic studies on the polymerization of 2-oxazolines, counteranion had little influence on the rate of propagation unless it was nucleophilic and changed the nature of the propagating species. $^{4,5}$

The oxazolinium ion having the tosylate counteranion $\mathbf{4 b}$ was prepared by the reaction of 1 with an excess amount of methyl tosylate as previously described. ${ }^{1}$ This salt was thermally stable and no isomerization took place upon heating. Although it was possible to determine the rate constant between the reaction of $\mathbf{4 b}$ and $\mathbf{1}$, we chose an easier and more appropriate way: propagation in the SIP of 1 with MeOTs was taken as a model reaction for the determination of the rate of propagation via $4 \mathbf{a}\left(k_{p 4}\right)$.

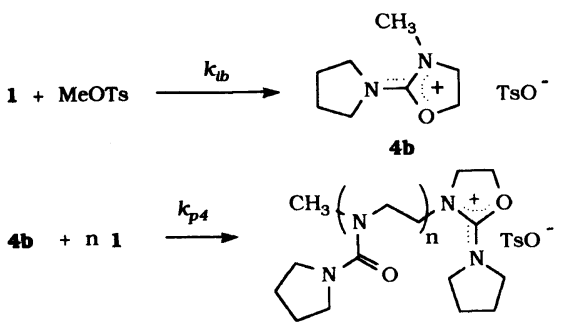

The rate of decrease of $\mathbf{1}$ in the SIP was 


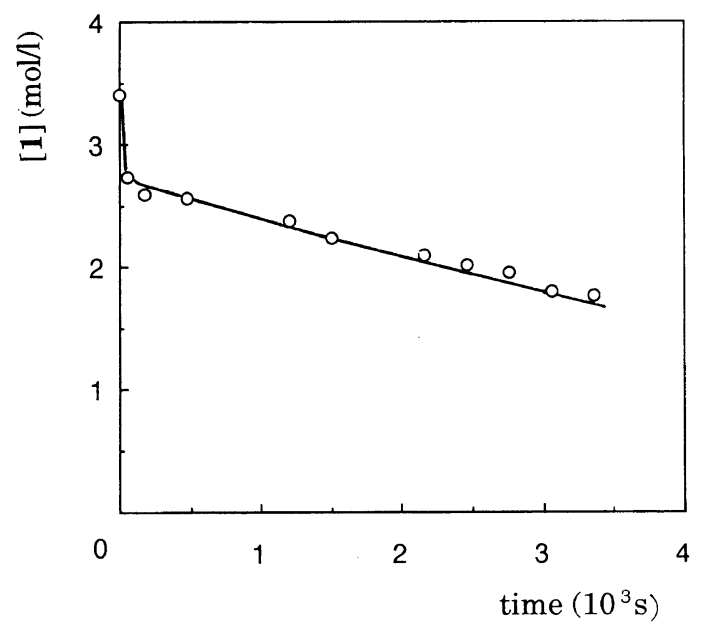

Figure 7. Time-course of the concentration of 1 by the SIP with MeOTs (in nitrobenzene- $d_{5}$ at $80^{\circ} \mathrm{C},[\mathrm{M}]_{0}=2.74$ $\mathrm{moll}^{-1},[\mathrm{I}]_{0}=0.538 \mathrm{moll}^{-1}$ ).

expressed by the following equation where $\left[\mathrm{P}^{*}\right]$ denotes the concentration of propagating species. Equation 12 has been used for the determination of $k_{p}$ in the polymerizations of cyclic imino ethers as well as cyclic iminocarbonates and is found to be also applicable to the present system, successfully.

$$
-\frac{\mathrm{d}[\mathrm{M}]}{\mathrm{d} t}=k_{i}[\mathrm{I}][\mathrm{M}]+k_{p}[\mathrm{P} *][\mathrm{M}]
$$

Figure 7 shows the time-course of the concentration of 1 in the polymerization by methyl tosylate at $80^{\circ} \mathrm{C}$, where $[\mathrm{M}]_{0} /[\mathrm{I}]_{0}$ was set to 5.2. The initial drop of the concentration of 1 was due to the initiation. The rate of initiation for the SIP of 1 with MeOTs at $35^{\circ} \mathrm{C}$ was $1.4 \times 10^{-3}\left(1 \mathrm{~mol}^{-1} \mathrm{~s}^{-1}\right)$ in an independent experiment using excess amounts of initiator and the subsequent calculation according to eq 3.

After the rapid consumption of the initiator, the contribution of the first term of the right-hand side of eq 12 becomes negligible. If the concentration of the propagating species is assumed equal to the initial concentration of initiator and constant during the propagation, which is highly likely in the present case of low
$[\mathrm{M}]_{0} /[\mathrm{I}]_{0}$ ratio, the rate of polymerization is expressed by the following equations.

$$
\begin{gathered}
-\frac{\mathrm{d}[\mathrm{M}]}{\mathrm{d} t}=k_{p}[\mathrm{I}]_{0}[\mathrm{M}] \\
\ln \frac{[\mathrm{M}]_{0}}{[\mathrm{M}]}=k_{p}[\mathrm{I}]_{0} t
\end{gathered}
$$

A linear plot was obtained from the data indicated in Figure 7 by applying eq 14 and the rate of polymerization $k_{p 4}$ at $80^{\circ} \mathrm{C}$ was $1.8 \times 10^{-4} 1 \mathrm{~mol}^{-1} \mathrm{~s}^{-1}$ from the slope. The constant at $35^{\circ} \mathrm{C}$ was determined as $8.3 \times$ $10^{-6} 1 \mathrm{~mol}^{-1} \mathrm{~s}^{-1}$.

As a model compound for $\mathbf{6 a}$, we prepared 3-methyl-1-azonia-3-azaspiro[4-4]nonan2-one tosylate $(\mathbf{6 b})$ by the reaction of $\mathbf{6 a}$ with silver tosylate. $6 \mathrm{~b}$ is white crystals having $158^{\circ} \mathrm{C}$ of melting point. It was thermally stable and no isomerization took place upon heating at $80^{\circ} \mathrm{C}$ for $24 \mathrm{~h}$ in nitrobenzene- $d_{5}$.

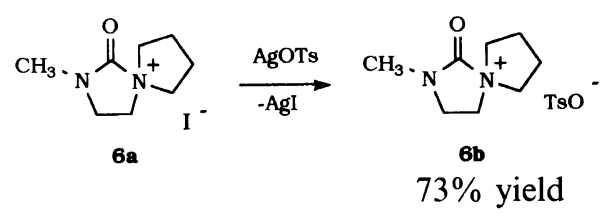

Scheme 4.

The rate constant for the reaction between $\mathbf{1}$ and $\mathbf{6 b}\left(k_{p 6}\right)$ at $80^{\circ} \mathrm{C}$ was determined by applying eq 3 to the obtained data. This value as well as the value at $35^{\circ} \mathrm{C}$ are summarized in Table II.

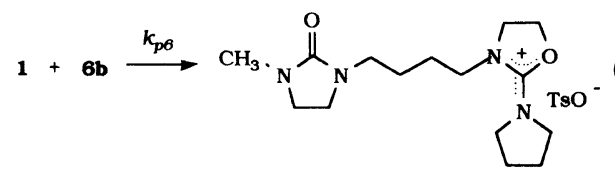

As for 7a, a $\delta$-substituted butyl iodide was considered not suitable as a model compound since the $\delta$-substituent attacks the $\alpha$ methylene carbon to produce an ionic species, and accelerates the propagation (so-called neighboring group participation). Therefore, $n$-butyl iodide was chosen as the model 
compound for $7 \mathrm{a} . k_{p 7}$ at 35 and $80^{\circ} \mathrm{C}$ are also shown in Table II.

$$
\mathrm{BuI}+1 \stackrel{k_{p 7}}{\longrightarrow}\left[\mathrm{N}-\sim_{\mathrm{O}}^{\mathrm{N}}+{ }_{\mathrm{I}}^{-}\right.
$$

\section{Total Kinetic Aspect of DIP}

The observed and estimated rate constants at $80^{\circ} \mathrm{C}$ are summarized in Scheme 5 to grasp the total image of the propagation in the DIP. The polymerization begins by rapid initiation. Produced 4a reacts with 1 to form the pendant unit or isomerized to $\mathbf{6 a}$. Under our experimental conditions, in which $[1]_{0}$ is around $4 \mathrm{moll}^{-1}$, the isomerization proceeds predominantly. $6 \mathbf{a}$ rapidly isomerized to $7 \mathbf{a}$ and gives an equilibrated mixture of $\mathbf{6 a}$ and $7 \mathbf{a}$. The formation of $\mathbf{7 a}$ becomes much more advantageous with rise in polymerization temperature. Although $6 \mathbf{a}$ and $7 \mathbf{a}$ concern the propagation to yield the main-chain-type unit, the contribution of $7 \mathbf{a}$ is larger than that of $\mathbf{6 a}$ because of its higher reactivity and concentration.

The rate constants regarded in this work are those for the initial propagating species to be exact. If the reactivities of $\mathbf{2}$ to $\mathbf{7}$ species at the

Initiation<smiles>C1CCN(C2=NCCO2)C1</smiles>
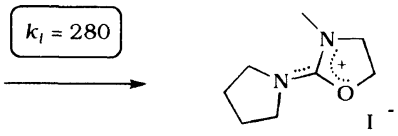

$4 a$

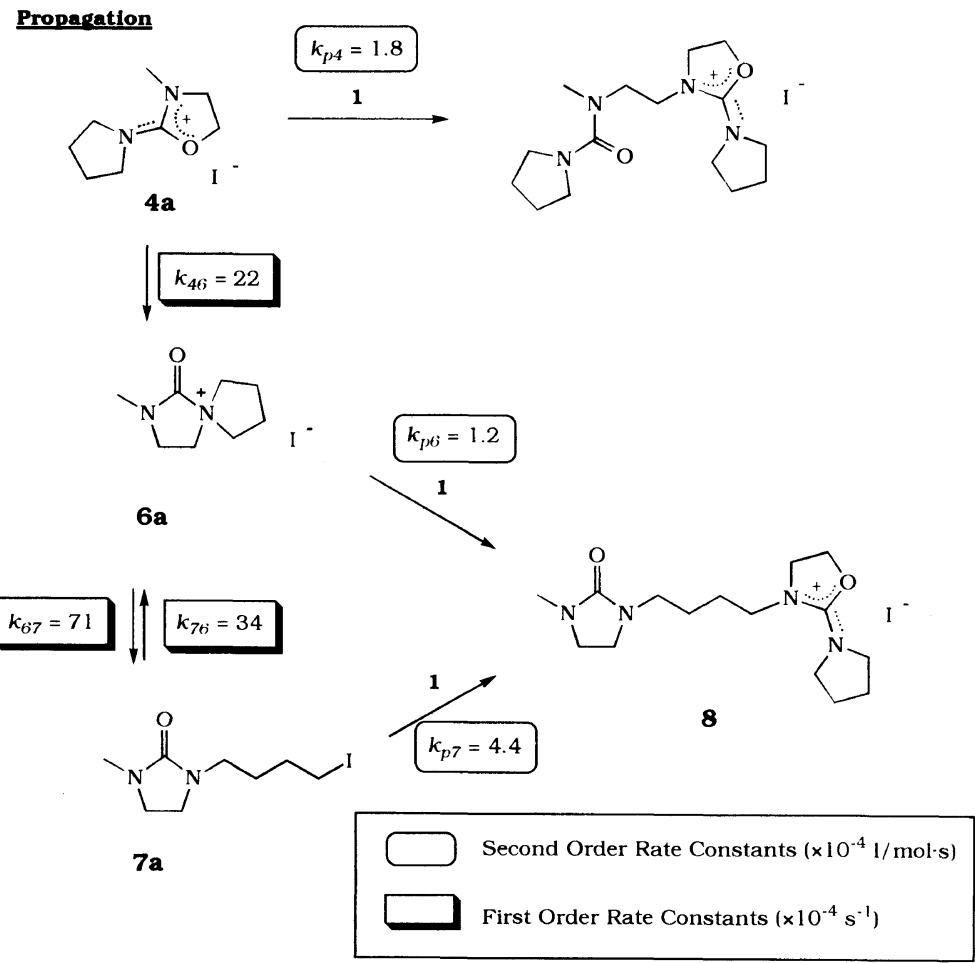

Scheme 5. 
polymer propagating end have the same reactivities as the corresponding model compounds, $\mathbf{2 a}-\mathbf{7 a}$, the total rate of polymerization can be determined from these constants. In Figure 8, the observed

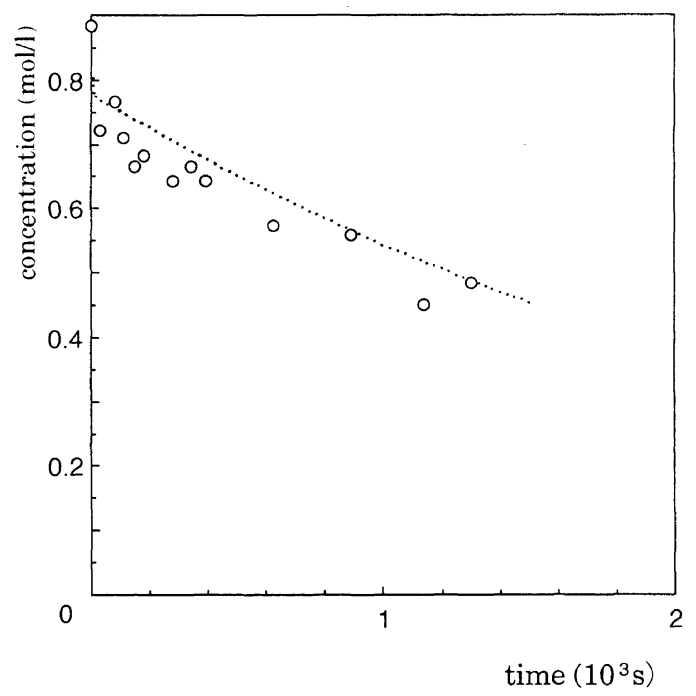

Figure 8. Consumption of 1 in the DIP with MeI (in nitrobenzene at $80^{\circ} \mathrm{C},[\mathrm{M}]_{0}=0.883 \mathrm{moll}^{-1},[\mathrm{I}]_{0}=0.143$ mol1 $\left.1^{-1}\right)$. Open circles show observed values and dotted line indicates the calculated values based on the rate constants summarized in Scheme 5. time-course of the concentration of $\mathbf{1}$ in the DIP with $[\mathrm{M}]_{0} /[\mathrm{I}]_{0}=10$ is compared with that based on calculation. In this experiment the monomer concentration was determined by GLC analysis because of its complicated ${ }^{1} \mathrm{H}$ NMR spectra. The observed data were not so reliable due to the adsorption of $\mathbf{1}$ on Silicon DC 550 in spite of precaution to avoid it. The observed rate of polymerization is similar to or slightly higher than the calculated one.

By using the individual rate constants it is possible to estimate polymer composition. Obviously, polymer composition depends on initial concentration and conversion of $\mathbf{1}$. Figure 9 illustrates the dependence of polymer composition on monomer conversion where $[\mathrm{M}]_{0}$ is set to $4 \mathrm{moll}^{-1}$ and $[\mathrm{M}]_{0} /[\mathrm{I}]_{0}$ is 10 . In an early stage of polymerization a polymer containing a relatively large amount of the pendant unit is produced, but its content decreases with increasing monomer conversion and finally reaches $14 \%$. In the figure the observed polymer compositions are shown as open circles, indicating the high reliability of the calculation.

The dependence of polymer composition on

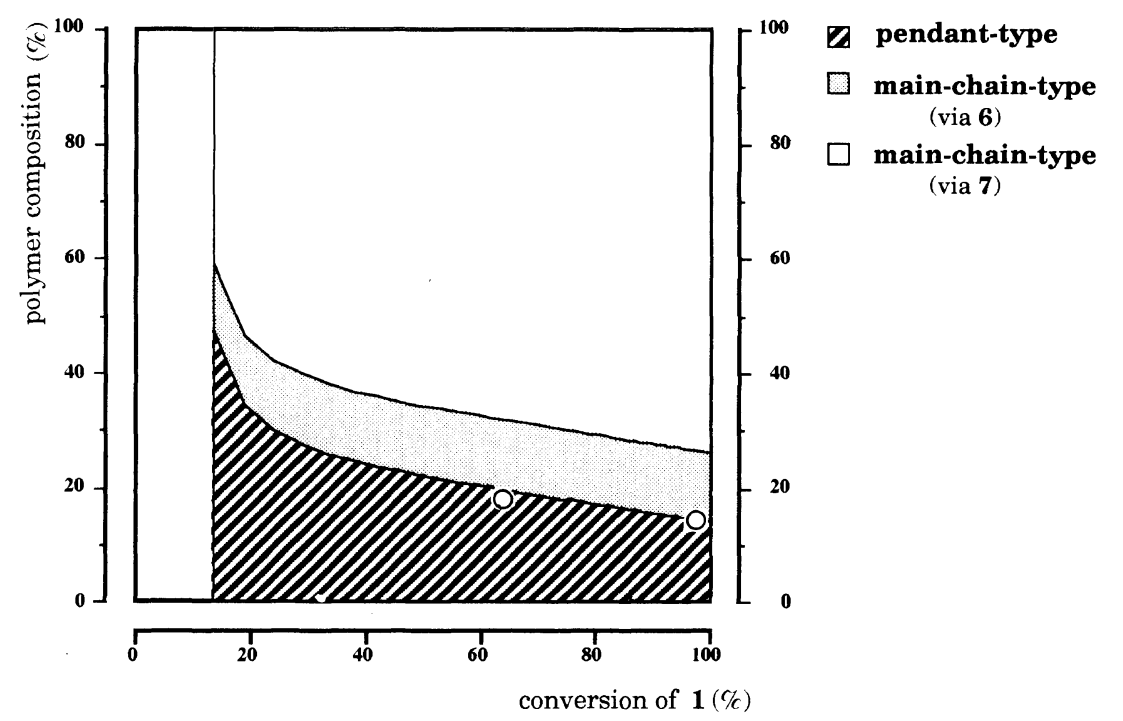

Figure 9. Calculated relationship between polymer composition as a function of the monomer conversion (in nitrobenzene at $80^{\circ} \mathrm{C},[\mathrm{M}]_{0}=4 \mathrm{moll}^{-1},[\mathrm{I}]_{0}=0.4 \mathrm{moll}^{-1}$ ). Open circles show observed compositions under these conditions. 


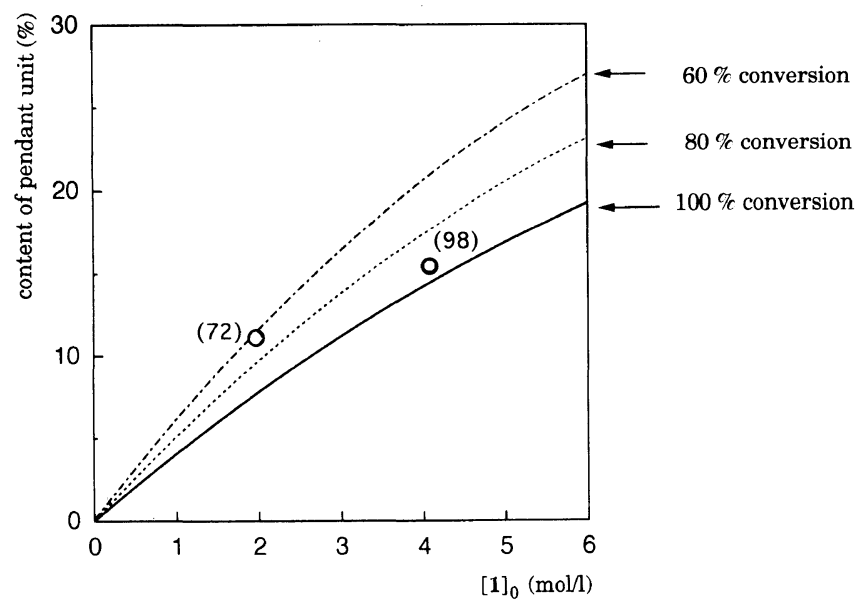

Figure 10. Relationship between the initial concentration of monomer and the polymer composition (in nitrobenzene at $80^{\circ} \mathrm{C}$ with $[\mathrm{M}]_{0} /[\mathrm{I}]_{0}=10$ ). Calculated values for 60,80 , and $100 \%$ monomer conversion are showed by lines and open circles indicates observed ones. Values in parentheses show polymer yields.

the initial concentration of monomer is shown in Figure 10. The three lines indicate the calculated polymer compositions when the monomer conversions are 60,80 , and $100 \%$. The observed values are also shown as open circles in the figure. With decrease in the initial monomer composition from 4 to $2 \mathrm{moll}^{-1}$, the content of the pendant group decreased from 16 to $11 \%$ and the polymer yield dropped from $98 \%$ to $72 \%$ simultaneously, which was attributed to the reduced rate of polymerization by dilution. The observed values agreed well with the calculated values, which show high reliability of the observed rate constants.

The polymerization kinetics are generally discussed from four aspects: initiation, propagation, chain transfer, and termination. In the present work, contributions of chain transfer and termination to the polymerization are ignored since the rate constants for them are difficult to determine by the methods we chose and polymerization is complicated without considering these problems.

When benzyl bromide or chloride was used as initiator, pure main-chain-type polymer 3 was obtained selectively. Nucleophilicity among halide ions in an aprotic solvent is $\mathrm{Cl}>\mathrm{Br}>\mathrm{I}$ and the leaving ability is $\mathrm{I}>$
$\mathrm{Br}>\mathrm{Cl}^{8}$ Therefore, the rate of isomerization $k_{46}$ greatly increases when the counteranion is changed from iodide to bromide or chloride while the rate constant $k_{p 4}$ is not much affected, which results in the selective formation of the main-chain-type unit. The change of initiator will also influence subsequent isomerization. The formation of the 7 like covalent species becomes more predominant as changing the counteranion from iodide to bromide and to chloride, but, concurrently, covalent species become more stable. Therefore it is difficult to elucidate the relative contribution of the propagating species in the DIP with benzyl chloride or bromide initiator without further kinetics studies, which will be described elsewhere.

\section{REFERENCES}

1. M. Miyamoto, K. Aoi, S. Yamaga, and T. Saegusa, Macromolecules, 25, 5111 (1992). M. Miyamoto, M. Shimakura, K. Tsutsui, K. Hasegawa, K. Aoi, S. Yamaga, and T. Saegusa, Macromolecules, in print.

2. M. Miyamoto, H. Amii, K. Aoi, and T. Saegusa, Macromolecules, 26, 1474 (1993).

3. For example, see: S. Kobayashi and T. Saegusa, "Ring-Opening Polymerization," Vol. 2, Elsevier Applied Science Publishers, New York, N.Y., 1985, 


\section{Kinetic Study on Double Isomerization Polymerization}

Chapter 11.

4. M. Miyamoto, K. Aoi, and T. Saegusa, submitted to Macromolecules.

5. M. Miyamoto, K. Aoi, and T. Saegusa, Macromolecules, 24, 11 (1991).

6. T. Saegusa, H. Ikeda, and H. Fujii, Macromolecules, 5, 359 (1972). T. Saegusa, H. Ikeda, and H. Fujii, Macromolecules, 6, 315 (1973). T. Saegusa, S.
Kobayashi, and Y. Nagura, Macromolecules, 7, 365 (1974).

7. S. Kobayashi, T. Tokuzawa, and T. Saegusa, Macromolecules, 15, 707 (1982).

8. For example, see: J. March, "Advanced Organic Chemistry 3rd," ed, Wiley-Interscience, New York, N.Y., 1985, p 308 and p 315. 